\title{
Conditions for Propagation of Air Inflammation in the Reactor with Reflecting Walls
}

\author{
Fedotov VG* \\ NN Semenov Institute of Chemical Physics of Russian Academia of Sciences, Russia \\ *Corresponding author: Fedotov VG, NN Semenov Institute of Chemical Physics of Russian Academia of Sciences, Russia
}

\begin{tabular}{|c|c|}
\hline ARTICLE INFO & ABSTRACT \\
\hline Received: 蔧 March 22, 2019 & \multirow{3}{*}{$\begin{array}{l}\text { The propagation of the air inflammation is observed at atmospheric pressure in the } \\
55 \mathrm{~cm} \text { long reactor with reflecting walls. The velocity of propagation is estimated to be } \\
\text { not less then } 100 \mathrm{~m} / \mathrm{s} \text {. These phenomena are explained by the role of electronically excit- } \\
\text { ed molecules in the mechanism of nitrogen oxidation chain reaction. }\end{array}$} \\
\hline Published: March 28, 2019 & \\
\hline Citation: Fedotov VG. Conditions for & \\
\hline $\begin{array}{l}\text { Propagation of Air Inflammation in the } \\
\text { Reactor with Reflecting Walls. Biomed } \\
\text { J Sci \& Tech Res 16(3)-2019. BJSTR. } \\
\text { MS.ID.002861. }\end{array}$ & $\begin{array}{l}\text { Keywords: The Propagation of Flame; Inflammation of Air; Electrical Discharge; Elec- } \\
\text { tronically Excited Molecules; NO (В 2П); } \mathrm{NO}_{2}{ }^{*}\end{array}$ \\
\hline
\end{tabular}

\section{Introduction}

This Article is concerning to investigation of Electronic Energy Explosion (EEE) in Air properties. The Phenomenon of EEE is described by exponential growth of electronically excited molecules concentration initiated by pulse periodic discharge with frequency $1000 \mathrm{~Hz}$ or by pulse of discharge near the surface of ferrite piece $[1,2]$. In the recent work [3] was found, that enhancing of Air pressure higher then $\mathrm{P}=1,3 \mathrm{~atm}$ at the initiation of EEE results in formation of active zone which propagates from the initiation region to whole the reactor volume. So, at air pressures lower then $1,3 \mathrm{~atm}$ the propagation of air inflammation is not observed, and at air pressures $\mathrm{P}>1,3 \mathrm{~atm}$-it can be observed. As the ability of flame to propagate is rising with the reaction rate rising, we can explain the effect of air pressure by participation of air molecules in the chain branching and termination processes of a nitrogen oxidation chain reaction. The Mechanism of nitrogen oxidation chain reaction [4] includes the reaction of electronically excited molecules $\mathrm{NO}_{2}{ }^{*}$ formation: $\mathrm{NO}+\mathrm{O}+\mathrm{M}=>\mathrm{NO}_{2}{ }^{*}+\mathrm{M}$. This gives for the stationary concentration of $\mathrm{NO}_{2}{ }^{*}[4]$ :

$$
\left[N O_{2} *\right]=k_{1}[M][O][N O] /\left(k_{o p t}[h v]+k_{2}\left[N O_{3}\right]+k_{q}[M]\right)
$$

Here $\mathrm{k}_{\mathrm{q}}$ - is the rate constant for electronically excited molecules quenching by collisions with $\mathrm{M}$ - the molecules of air mixture. $\mathrm{k}_{\mathrm{opt}}$ is the rate constant for stimulated emission of radiation, [hv]- is the photon concentration. $\mathrm{k}_{2}$ - is the rate constant for energy exchange between $\mathrm{NO}_{2}{ }^{*}$ and radicals $\mathrm{NO}_{3}$, which results in the decay of radicals:

$$
\mathrm{NO}_{2} *+\mathrm{NO}_{3}=>2 \mathrm{NO}_{2}+\mathrm{O}
$$

To explain the rising of electronically excited molecules concentration and the chain branching rate together with $[\mathrm{M}]$ it is necessary that the termination of such molecules does not depend on [M]. It is possible at high concentration of $\mathrm{NO}_{3}$ or (and) at high intensity of stimulated emission of radiation. The stimulated emission makes the main contribution to the radiation process in the EEE active medium $[5,6]$. So, we can assume that covering of reactor walls with some reflective material (the $\mathrm{Al}$ foil for example) can significantly better the conditions of air inflammation propagation after initiation of EEE by using of electric discharge near the surface of ferrite piece. The Aim of this work was the experimental proof of the assumption mentioned above.

\section{Methods of Experiments}

For the EEE initiation in this work was used the ferrite ring 16 $\mathrm{mm}$ in diameter (magnetic material with $\mu=2000$ ). Two electrodes made of steel were in contact with the ferrite surface. The distance between the contact points was 2-3 $\mathrm{mm}$. The first of these electrodes was connected to one pole of capacitors battery. A switch was placed between the second electrode and the second pole of the capacitor battery. Turning the switch in the "on" position resulted 
in applying of $440 \mathrm{~V}$ - total voltage on two $1000 \mu \mathrm{F}$ capacitors connected in sequence - to the electrodes contacting with the ferrite surface. This resulted in EEE initiation in the gap between electrodes. This arrangement (the ferrite ring with electrodes) was placed in the transparent plastic tube $55 \mathrm{~cm}$ in length, which can be seen at the Figure 1. The tube described above could be wrap up (or not wrap up) with the Al foil in such a manner that there remained a longitudinal slit in the foil. For the radiation from the tube registration the Xiaomi Action Camera (Mi Action Camera $4 \mathrm{k}$ Model : YDXJ01FM) was used, 200 frames/s was the rate of video recording by this action camera.

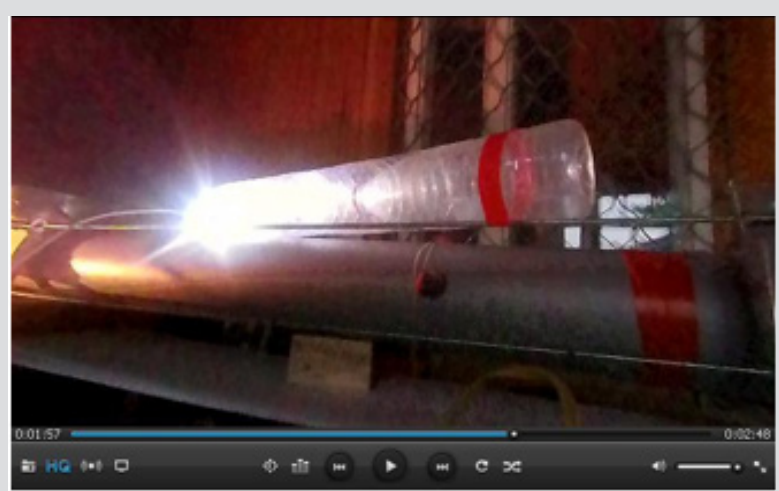

Figure 1: Here is one frame of video which contains the EEE image in the transparent tube without $\mathrm{Al}$ foil.

\section{Results of Experiments}

One frame of the video containing the image of EEE in the transparent plastic tube without $\mathrm{Al}$ foil is placed on the Figure 1. There can be seen that the active luminescent zone is located close to the initiation region. On the Figure 2 is placed a frame of video which contains the EEE image in the tube wrap up with $\mathrm{Al}$ foil. In this case the EEE active zone filled the entire volume of the tube. Thus, one can state that the inflammation of air propagates in the tube with reflecting walls at the atmospheric pressure.

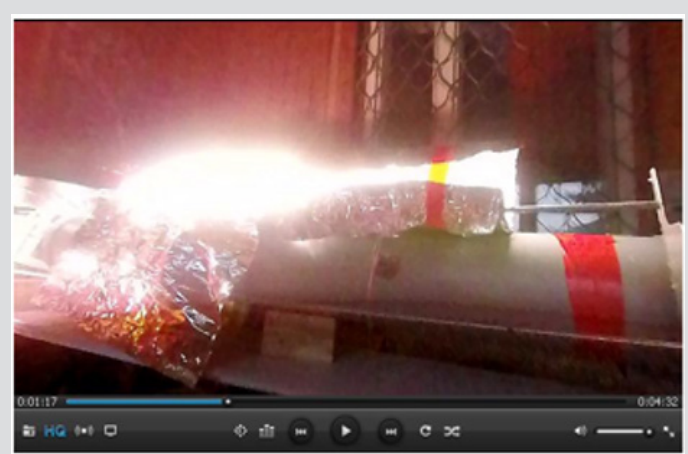

Figure 2: Here is one frame of the video which contains the EEE image in the transparent tube wrap up with $\mathrm{Al}$ foil.

\section{Discussion}

The obtained results give evidence that radiation of electronically excited molecules makes the main contribution to their deactivation. It is possible only in the case when the stimulated (not spontaneous) emission of radiation takes place. In the analogical experiment with EEE in the jerrican of 10 liter volume wrap up with $\mathrm{Al}$ foil at the air pressure $1.5 \mathrm{~atm}$ (Figure 3) was observed the red radiation coming through the slit in the foil to the white screen in the same time when the yellow radiation passes through the butt-ends of the jerrican (this radiation can contain the green and blue components). The red radiation can be attributed to $\mathrm{NO}_{2}{ }^{*}$ molecules, the green colored radiation comes from exiplexes $\mathrm{N}_{2}-\mathrm{O}\left({ }^{1} \mathrm{~S}\right)$, the blue radiation is produced by $\mathrm{NO}(\mathrm{B} 2 \mathrm{2})$ molecules. The yellow light spot can be seen at the screen opposite to the butt-end of the jerrican. The difference in the colors of radiation produced in different directions gives evidence for contribution of stimulated emission of radiation to observed process. There is one more fact worth of noting: the time needed for the air inflammation propagation at the $50 \mathrm{~cm}$ distance is not more than 5 milliseconds (this is the time of one frame of video formation). It gives for the speed of flame evaluation: $100 \mathrm{~m} / \mathrm{s}$. This value is higher than the known speed of flame in the one of the most fast burning mixtures $\left(75 \% \mathrm{H}_{2}+25 \% \mathrm{O}_{2}\right.$, the normal speed of burning in that mixture equals $10 \mathrm{~m} / \mathrm{s}$ [7]). The explanation of that fact can relate to the higher velocity of hot NO molecules, which are formed in the process of vibration energy deactivation. The main contribution to the radiation of NO (B 2П) molecules make the optical transitions $($ В $2 \Pi, v=0,1,2) \rightarrow\left(X 2 \Pi, v^{\prime}=10, \ldots, 15\right)[1]$.

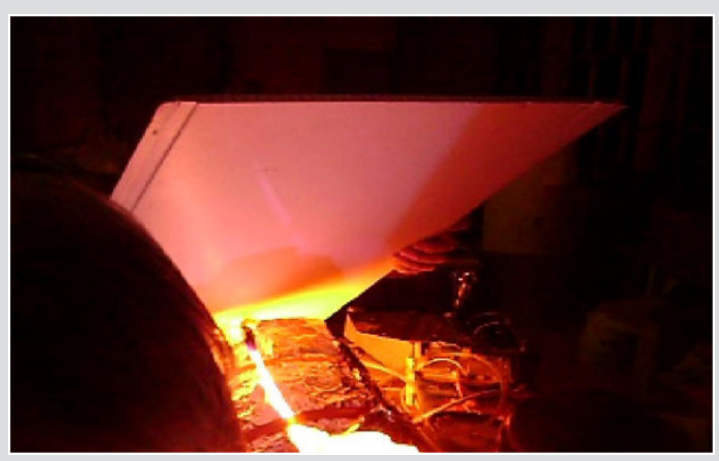

Figure 3: EEE in the jerrican of 10-liter volume. The white screen is illuminated by red colored radiation coming from the slit in the $\mathrm{Al}$ foil.

These transitions result in formation of NO molecules at high levels of vibration energy: $v^{\prime}=10-15$. To loose such vibration energy the molecule should undergo 10-15 deactivating collisions, after each of them it will have the translational motion energy about $2 \mathrm{eV}$. That is two orders of magnitude more than average thermal energy of molecules at room temperature. The air inflammation propagation gives the method for nitrogen oxidation in the unrestricted volumes by spending restricted amounts of energy. Using of reflecting walls of the reactor is simpler technologically then creation of hermetic reactor for the pressures as high as $1.5 \mathrm{~atm}$.

\section{References}

1. Fedotov VG, Fedotova EY (2015) Explosion in atmospheric air initiated by electric discharge and associated with the growth of the concentrations of electronically excited molecules and free charges. Russian J Phys Chem B 9(2): 223-227. 
2. Fedotov VG, Fedotova EY (2015) The chain reaction of atmospheric nitrogen oxidation, initiated by electric discharge in air. J Phys Chem \& Biophys 5(6): 195.

3. Fedotov VG, Fedotova EY (2018) Conditions for propagation of air inflammation. Biomed J Scien Technol Res 11(2): 002074.

4. Fedotov VG, Fedotova EY (2016) Chemical Kinetic Model of the chain reaction of atmospheric nitrogen oxidation initiated by electric discharge. Russian J Phy Chem 10(5): 748-752.

\section{ISSN: 2574-1241}

DOI: 10.26717/BJSTR.2019.16.002861

Fedotov VG. Biomed J Sci \& Tech Res

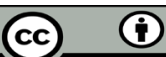

This work is licensed under Creative Commons Attribution 4.0 License

Submission Link: https://biomedres.us/submit-manuscript.php
5. Fedotov VG, Fedotova EY (2017) The inversed populations in the active medium of Electronic Energy Explosion (EEE) in the air. J Phys Astron 5(1): 106.

6. Fedotov VG, Fedotova EY (2017) Multicolor laser generation resulting from a chain reaction of atmospheric nitrogen oxidation initiated by an electric discharge in air. Russian J Phys Chem B 11(6): 928-931.

7. Kondratiev VN, Nikitin EE (1974) Kinetics and mechanism of gasofaznyh reakzii Science Moscow, pp. 488.

$\begin{array}{ll}\text { BIOMEDICAL } & \text { Assets of Publishing with us } \\ \text { RESEARCHES } & \text { - Global archiving of articles } \\ & \text { - Immediate, unrestricted online access } \\ \end{array}$

